\title{
Junctional bradycardia is a potential risk factor of stroke
}

\author{
Gwang Sil Kim', Jae-Sun Uhm', Tae-Hoon Kim, Hancheol Lee, Junbeom Park, Jin-Kyu Park, Boyoung Joung, \\ Hui-Nam Pak and Moon-Hyoung Lee*
}

\begin{abstract}
Background: This study aimed to determine the risk of thromboembolic events in patients with junctional bradycardia(JB).

Methods: We retrospectively reviewed electrocardiograms(ECGs) for 380,682 patients. Those with JB on an ECG at least twice over a $\geq 3$-month interval were included for analysis. We additionally included $138 \mathrm{CHADS}_{2}$ scorematched patients(age, $68.4 \pm 15.7$ years; male, $52.2 \%$ ) in sinus rhythm as a control group. Between the JB patients(with or without retrograde P wave) and controls, we compared incidences of ischemic stroke and a composite of ischemic stroke, renal infarction, ischemic colitis, acute limb ischemia, and pulmonary embolism.

Results: Among 380,682 patients (age, $47.6 \pm 19.9$ years; male, $49.3 \%$ ), 69 patients (age, $68.5 \pm 16.5$ years; male, $50.7 \%$ ) exhibited JB on an ECG at least twice over a $\geq 3$-month interval; the overall prevalence of JB was $0.02 \%$. The mean followup period was $27.2 \pm 26.2$ months. Forty-five patients (65.2 \%) in the JB group had no retrograde P wave. Ischemic stroke incidence was significantly higher in JB patients without a retrograde $\mathrm{P}$ wave than in controls (6/45 patients [13.3 \%] and $3 / 138$ patients [2.2\%], respectively; $P=0.007$ ). The incidence of composite thromboembolic events was also significantly higher in JB patients without a retrograde $P$ wave than in controls (8/45 patients [17.8 \%] and 4/138 patients [2.9\%], respectively; $P=0.011$ ). In a Cox proportional hazards model, JB patients without a $P$ wave showed a greater incidence of stroke (hazard ratio, 8.89 [2.20-33.01], $P=0.007$ ) than controls and JB patients with a P wave.
\end{abstract}

Conclusions: Junctional bradycardia is potentially associated with ischemic stroke, particularly in the absence of an identifiable retrograde $\mathrm{P}$ wave.

Keywords: Junctional bradycardia, Thromboembolic events, Stroke

\section{Background}

Junctional bradycardia (JB) involves cardiac rhythms that arise from the atrioventricular junction at a heart rate of $<60 /$ min. In patients with retrograde atrioventricular nodal conduction, a retrograde $\mathrm{P}$ wave can be accompanied with JB. The event occurs as enhanced automaticity or as an escape rhythm during significant bradycardia with rates slower than the intrinsic junctional pacemaker [1]. JB can appear in patients with sick sinus syndrome or those with significant bradycardia that allows the atrioventricular nodal region to determine the heart rate [2]. As most of these patients are asymptomatic, there are no

\footnotetext{
* Correspondence: mhlee@yuhs.ac

${ }^{\dagger}$ Equal contributors

Department of Cardiology, Severance Cardiovascular Hospital, Yonsei University College of Medicine, 50-1 Yonsei-ro Seodaemun-gu, Seoul, Republic of Korea
}

\section{Methods}

We retrospectively reviewed electrocardiograms (ECGs) for 380,682 patients (47.6 \pm 19.9 years; male, $49.3 \%$ ) from a single university hospital from January 2008 to December 2012. We screened consecutive patients who visited our outpatient center or were admitted to our hospital for ECG recording during the period. We initially excluded patients who were admitted due to acute myocardial infarction or acute stroke and patients whose life expectancy is less than 6 months due to cancer. A 
total of 972,683 ECGs (mean of 2.55 ECGs per patient) stored in our electronic database system (Muse System, General Electric Healthcare, Milwaukee, Wisconsin, USA) were included in this study. Twelve-lead ECGs were recorded by digital ECG instruments (General Electric Healthcare, Milwaukee, Wisconsin, USA). The digital sampling rate was 500 samples per second. The low and high cut-off frequencies were 0.5 and $100 \mathrm{~Hz}$, respectively. Initially, the ECGs were screened by an automated ECG analysis algorithm embedded in our system to detect for JB. The algorithm for detecting JB is as follows: no $\mathrm{P}$ wave, a regular $\mathrm{RR}$ interval (i.e., an $\mathrm{RR}$ interval range that is less than $10 \%$ of the average $R R$ interval), narrow primary beat $(<0.12 \mathrm{~s}$ for QRS duration), and a regular rate less than 60 beats $/ \mathrm{min}$. Then, three cardiologists reviewed the screened ECGs and finally selected those exhibiting JB in accordance with the following: JB was defined as a regular rhythm of less than 60 beats/min without a precedent $P$ wave and a narrow QRS complex for a duration of less than $0.12 \mathrm{~s}$. Retrograde P wave was defined as an inverted P wave after the QRS complex was noted. Respective ECGs with $\mathrm{JB}$, with or without a retrograde $\mathrm{P}$ wave, were to be agreed upon by all three cardiologists. Inclusion criteria for analysis comprised age older than 18 years and JB on multiple ECGs at an interval of at least 3 months. Patients with transient JB and those with hyperkalemia at the time of ECG recording, history of end-stage renal disease, paroxysmal atrial fibrillation, and only one recording of JB were excluded. Additionally, patients who had been treated with implantation of a pacemaker or cardiac resynchronization therapy due to sick sinus syndrome or intractable heart failure were excluded from analysis.

Additionally, we also included 138 age-, gender-, and $\mathrm{CHADS}_{2}$ score-matched patients in sinus rhythm as a control group; these patients had undergone minor surgery, including nasal septal deviation and cataract surgery, in the same period and at the same hospital. For the controls, we excluded patients with a history of thromboembolic events, including ischemic stroke, and those lacking two-dimensional transthoracic echocardiographs. Since the incidence of JB was very low we aimed for 1:2 matching. In addition, to minimize confounding factors, we matched age, gender, and $\mathrm{CHADS}_{2}$ score, which are known as risk factors for stroke not only in patients with atrial fibrillation but also in patients without atrial fibrillation. $\mathrm{CHADS}_{2}$ score was calculated for each patient by assigning 1 point each for an age $\geq 75$ years, history of heart failure, hypertension, and diabetes mellitus and 2 points for previous stroke or transient ischemic attack. Ischemic stroke was defined as symptomatic ischemic cerebral infarction with an apparent brain lesion on imaging studies. Beginning of follow-up was defined as time of acquisition of $2^{\text {nd }}$ ECG in JB group and acquisition of $1^{\text {st }}$ ECG in control group. Transient ischemic attack (TIA) was defined as a neurologist-confirmed transient episode of neurologic dysfunction without a brain lesion on imaging studies. Two-dimensional transthoracic echocardiography was performed using an ultrasound machine (Vivid 7, GE Medical Systems, Horten, Norway and Sonos 5500, Philips Medical Systems, Andover, Massachusetts, USA) with a $2.5-\mathrm{MHz}$ transducer. Left atrial volume index was calculated by the prolate ellipsoid method $[5,6]$. Left ventricular ejection fraction was measured using the modified Simpson's method [5] on images of apical, 2- and 4-chamber views. Echocardiographic findings were reviewed by three cardiologists. Clinical characteristics; medication history; laboratory and imaging data; and development of ischemic stroke, transient ischemic attack, renal infarction, ischemic colitis, acute limb ischemia, and pulmonary embolism were reviewed from electronic medical records. JB was re-classified into two groups according to the presence of a retrograde $\mathrm{P}$ wave: JB without a retrograde $\mathrm{P}$ wave (JB without $\mathrm{P}$ ) group and $J B$ with a retrograde $\mathrm{P}$ wave (JB with $\mathrm{P}$ ) group. The primary endpoint was ischemic stroke and transient ischemic attack. The secondary endpoint was a composite of ischemic stroke, transient ischemic attack, renal infarction, ischemic colitis, acute limb ischemia, and pulmonary embolism. We compared the incidences of the primary and secondary endpoints between the JB and control groups, as well as between the JB without $\mathrm{P}$ and JB with $\mathrm{P}$ groups. We calculated hazard ratios of JB for primary and secondary endpoints in comparison to sinus rhythm. We also calculated hazard ratios of JB without a retrograde $\mathrm{P}$ wave for primary and secondary endpoints in comparison to JB with a retrograde $\mathrm{P}$ wave. The study design was approved by the Institutional Review Board of Severance Hospital and conducted in compliance with the Declaration of Helsinki. The requirement for informed consent was waived, because of the retrospective nature of the study.

\section{Statistical analysis}

Continuous variables are expressed as mean \pm standard deviation, and categorical variables as numbers (percentages). Mann-Whitney and Fisher's exact test were used for comparisons of continuous and categorical variables, respectively. Kaplan-Meier curves were constructed for time to event and compared by log-rank tests confined to 2 years of follow-up. Univariable and mutivariable Cox proportional hazards models were used to compare hazard ratios for primary and secondary endpoints between groups. The log-minus-log-survival function was used to assess the proportional hazards assumption and found that it was reasonable. Hazard ratios (HR) and $95 \%$ confidence intervals (CI) were calculated. Two-sided $p$ values $<0.05$ were considered statistically significant. The data were analyzed 
using the Statistical Package for the Social Sciences, version 20.0 (IBM Inc., Armonk, NY, USA).

\section{Results \\ Population}

The overall prevalence of JB for all 380,682 patients screened was $0.02 \%$ in the present study. In total, 75 patients showed JB on ECGs twice over an interval of at least 3 months. Two patients had undergone implantation of pacemaker device and were excluded from analysis. An additional 4 patients who underwent cardiac surgery were excluded due to anticoagulation therapy that was maintained after valve surgery and clinical events that occurred during the immediate postoperative period. Finally, we included 69 patients (age, $68.5 \pm 16.5$ years; male, $50.7 \%$ ) with JB on ECGs. Among these, 40 patients (58 \%) had been admitted; 29 patients (73\%) were admitted due to cardiovascular disease (14 patients with coronary artery disease, 7 patients with valvular heart disease, and 7 patients with myocardial disease). Of the 69 patients, three $(4.3 \%)$ had symptoms that might be associated with JB: two complained of orthostatic dizziness at an outpatient center. Their ECG revealed JB without a retrograde $\mathrm{P}$ wave. The other patient had a history of syncope, assumedly vasovagal syncope, and her ECG revealed JB with a retrograde P wave. These patients, however, did not receive any specific treatment, including pacemaker implantation. We also included 138 age-, gender-, and $\mathrm{CHADS}_{2}$ score-matched patients (age, 68.4 \pm 15.7 years; male, $52.2 \%)$ as a control group. Baseline characteristics for both groups are presented in Table 1 . Thirty patients $(43.5 \%)$ underwent Holter monitoring and had no evidence of atrial fibrillation. The patients in the JB and control groups were followed for $27.2 \pm$ 26.2 months and $25.4 \pm 21.5$ months, respectively, and $44.9 \%$ of the patients had a $\mathrm{CHADS}_{2}$ score $\geq 2$. Chronic kidney disease was significantly more frequent in the JB group than in the control group $(P=0.042)$. Left atrial volume index was significantly greater in the JB group than in the control group $(P=0.001)$. There were no significant differences in age, sex, comorbidities (hypertension, diabetes, heart failure, coronary artery disease, and stroke) or ejection fraction between the JB and control groups.

Table 1 Baseline characteristics

\begin{tabular}{|c|c|c|c|c|c|c|}
\hline & $\begin{array}{l}\text { JB group } \\
(n=69)\end{array}$ & $\begin{array}{l}\text { Control group } \\
(n=138)\end{array}$ & $P$ value* & $\begin{array}{l}\text { JB with } \mathrm{P} \text { group } \\
(n=24)\end{array}$ & $\begin{array}{l}\text { JB without } P \text { group } \\
(n=45)\end{array}$ & $P$ value ${ }^{* *}$ \\
\hline Age (years) & $68.5 \pm 16.5$ & $68.4 \pm 15.7$ & 0.593 & $67.3 \pm 16.6$ & $69.2 \pm 16.5$ & 0.273 \\
\hline Men, $n(\%)$ & $35(50.7)$ & $72(52.2)$ & 0.883 & $10(41.7)$ & $25(55.6)$ & 0.318 \\
\hline Smoking, $n(\%)$ & $26(37.7)$ & $40(29.0)$ & 0.210 & $8(33.3)$ & $18(40.0)$ & 0.614 \\
\hline Hypertension, n (\%) & $39(56.5)$ & $76(55.1)$ & 0.883 & $11(45.8)$ & $28(62.2)$ & 0.213 \\
\hline Diabetes mellitus, $n(\%)$ & $30(43.5)$ & $50(36.2)$ & 0.364 & $8(33.3)$ & $22(48.9)$ & 0.308 \\
\hline Heart failure, $n(\%)$ & $6(8.7)$ & $11(8.0)$ & $>0.999$ & $3(12.5)$ & $3(6.7)$ & 0.412 \\
\hline Chronic kidney disease, $n$ (\%) & $20(29.0)$ & $22(15.9)$ & 0.043 & $5(20.8)$ & $15(33.3)$ & 0.404 \\
\hline History of CAD, $n(\%)$ & $21(30.4)$ & $44(31.9)$ & 0.875 & $3(12.5)$ & $18(40.0)$ & 0.027 \\
\hline History of stroke, $n(\%)$ & $1(1.4)$ & $1(0.7)$ & $>0.999$ & $0(0.0)$ & $1(2.2)$ & $>0.999$ \\
\hline Ejection fraction (\%) & $64.2 \pm 11.3$ & $63.3 \pm 11.0$ & 0.485 & $63.8 \pm 13.4$ & $64.4 \pm 10.1$ & 0.772 \\
\hline LAVI $\left(\mathrm{ml} / \mathrm{m}^{2}\right)$ & $45.1 \pm 30.3$ & $28.0 \pm 11.3$ & 0.001 & $40.8 \pm 10.4$ & $47.1 \pm 36.1$ & 0.740 \\
\hline Antiplatelet agents, $n$ (\%) & $33(47.8)$ & $101(73.2)$ & 0.883 & $9(37.5)$ & $24(53.3)$ & 0.312 \\
\hline Statin, $n(\%)$ & $26(37.7)$ & $52(37.7)$ & $>0.999$ & $7(29.2)$ & $19(42.2)$ & 0.312 \\
\hline Anticoagulants, $n(\%)$ & $8(11.6)$ & $6(4.3)$ & 0.091 & $2(8.3)$ & $6(13.3)$ & 0.704 \\
\hline $\mathrm{CHADS}_{2}$ score & $1.48 \pm 1.16$ & $1.49 \pm 1.19$ & 0.991 & $1.17 \pm 1.13$ & $1.64 \pm 1.15$ & 0.103 \\
\hline $0, n(\%)$ & $16(23.2)$ & $32(23.2)$ & & $8(33.3)$ & $8(17.8)$ & \\
\hline $1, n(\%)$ & $22(31.9)$ & $44(31.9)$ & & $8(33.3)$ & $14(31.1)$ & \\
\hline $2, n(\%)$ & $16(23.2)$ & $32(23.2)$ & & $5(20.8)$ & $11(24.4)$ & \\
\hline $3, n(\%)$ & $12(17.4)$ & $24(17.4)$ & & $2(8.3)$ & $10(22.2)$ & \\
\hline $4, n(\%)$ & $3(4.3)$ & $6(4.3)$ & & $1(4.2)$ & $2(4.4))$ & \\
\hline Follow-up duration (month) & $27.2 \pm 26.2$ & $25.4 \pm 21.5$ & 0.948 & $39.3 \pm 36.5$ & $20.7 \pm 15.6$ & 0.008 \\
\hline
\end{tabular}




\section{Thromboembolic events}

Incidences of thromboembolic events are summarized in Table 2. Thromboembolic events occurred in 8 patients $(17.8 \%)$ in the JB without $\mathrm{P}$ group. In contrast, thromboembolic events occurred in one (4.2\%) and 4 (2.9\%) patients in the JB with P group and the control group, respectively. Stroke and composite thromboembolic events were significantly more frequent in the JB without $\mathrm{P}$ group than the control and JB with $\mathrm{P}$ groups. Six patients $(13.3 \%)$ developed stroke in the JB without $\mathrm{P}$ group, and the time interval between detection of JB and the date the events occurred ranged from 1 month to 4 years. Among 6 patients, three had undergone cardiac surgery (coronary artery bypass graft in 2 patients and mitral valve repair in 1 patient). Their clinical events occurred 40 months, 31 months, and 7 months after cardiac surgery. We summarized the clinical history of patients who showed thromboembolic events in Table 3. We could not compare the incidences of renal infarction, ischemic colitis, acute limb ischemia, and pulmonary embolism due to their rare incidence. Using the Cox proportional hazards model, JB without retrograde P wave was significantly associated with both stroke and composite thromboembolic events, even after adjusting for confounding clinical factors, such as gender and $\mathrm{CHADS}_{2}$ score, as described on Table 4. After excluding TIA, JB without retrograde $\mathrm{P}$ wave was also associated with incidence of stroke in multivariable analysis, which included gender and $\mathrm{CHADS}_{2}$ score (hazard ratio, 5.062 [2.12-22.63], $P=0.034$ ).

Table 2 Thromboembolic events

\begin{tabular}{|c|c|c|c|c|c|}
\hline & $\begin{array}{l}\text { JB with } \\
\text { P group } \\
(n=24)\end{array}$ & $\begin{array}{l}\text { JB without } \\
\text { P group } \\
(n=45)\end{array}$ & $\begin{array}{l}\text { Control } \\
\text { group } \\
(n=138)\end{array}$ & $P$ value & $P$ value \\
\hline Stroke (\%) & 0 & $4(8.9)$ & $3(2.2)$ & & - \\
\hline TIA (\%) & 0 & $2(4.4)$ & 0 & & \\
\hline $\begin{array}{l}\text { Stroke and } \\
\text { TIA (\%) }\end{array}$ & 0 & $6(13.3)$ & $3(2.2)$ & $0.007^{*}$ & \\
\hline $\begin{array}{l}\text { Renal infarction, } \\
n(\%)\end{array}$ & $1(4.2)$ & 0 & 0 & - & - \\
\hline $\begin{array}{l}\text { Ischemic colitis, } \\
n(\%)\end{array}$ & 0 & 0 & $1(0.7)$ & - & - \\
\hline $\begin{array}{l}\text { Acute limb } \\
\text { ischemia, } n(\%)\end{array}$ & 0 & $1(2.2)$ & 0 & - & - \\
\hline $\begin{array}{l}\text { Pulmonary } \\
\text { embolism, } n \text { (\%) }\end{array}$ & 0 & $1(2.2)$ & 0 & - & - \\
\hline $\begin{array}{l}\text { Composite } \\
\text { thromboembolic } \\
\text { events, } n(\%)\end{array}$ & $1(4.2)$ & $8(17.8)$ & $4(2.9)$ & $0.011^{* *}$ & $0.059^{* * * *}$ \\
\hline
\end{tabular}

We compared the incidence of stroke or transient ischemic attack among the three groups using KaplanMeier curves over 48 months of follow-up, as shown in Fig. 1. A difference in event-free survival was noted in the early period of follow-up and did not decrease after follow-up for up to 48 months.

\section{Discussion}

In the present study, JB was found to be potentially associated with the occurrence of a composite of thromboembolic events. JB without a retrograde P wave was also shown to be a significant risk factor for both the occurrence of stroke and the composite of thromboembolic events.

Paroxysmal atrial fibrillation and sick sinus syndrome have been reported as risk factors for thromboembolic events, such as acute stroke [4, 7-9]. Paroxysmal atrial fibrillation is considered an earlier form of arrhythmia, showing less electrical and structural remodeling of the atria; nonetheless, the risk of thromboembolic events is similar for persistent or permanent atrial fibrillation. Accordingly, most current guidelines recommend the use of oral anticoagulation for patients with stroke risk factors, irrespective of the type of atrial fibrillation $[10,11]$. Sinus node dysfunction is also reported as a risk factor for stroke $[3,12]$. The annual incidence of stroke in patients with sick sinus syndrome is estimated at approximately $6-10 \%$, even after pacemaker implantation and physiologic pacing, such as DDD mode $[4,9,13]$. Virchow described a triad of abnormalities associated with thrombus formation: abnormal vessel wall, abnormal blood constituents, and abnormal flow [14]. Of these, ineffective atrial contraction could be associated with abnormal flow. Atrial performance is categorized into four phases: reservoir function, conduit function, active contractile pump function, and suction force [15]. In late diastole, the atrium behaves as a pump as pressure rises due to active atrial contraction and pushes the blood through the mitral valve, contributing 15-30\% to left ventricular filling [16, 17]. In a case report of thromboembolism in a patient with intermittent periods of sinus arrest and junctional escape bradycardia, spontaneous echo contrast was detected on transthoracic echocardiography [13]. Additionally, Vincelj et al. reported that spontaneous echo contrast is associated with left atrial enlargement, which is known as a risk factor for thromboembolism [18]. Thus, spontaneous echo contrast suggested that inactive atrial pumping might cause blood stagnation and could be associated with cardioembolic embolism.

We hypothesized that JB would show similar pathophysiology to atrial fibrillation and sick sinus syndrome in terms of ineffective atrial contraction, which may be a cardiogenic thromboembolic source. Our data indicated that JB without retrograde $\mathrm{P}$ wave is a robust risk factor for both stroke and thromboembolic events in multivariable analysis. However, the main pathogenic mechanism 
Table 3 Clinical information in patients with thromboembolic events

\begin{tabular}{lllllll}
\hline Patients number & Age & Sex & Group & $\begin{array}{l}\text { Heart rate } \\
(/ \mathrm{min})\end{array}$ & Thromboembolic events & Underlying disease \\
\hline 1 & 74 & Female & Control & 70 & Stroke & HTN, CAD \\
2 & 74 & Female & Control & 66 & Stroke & HTN, DM \\
3 & 80 & Male & Control & 80 & Ischemic colitis & HTN, DM \\
4 & 79 & Male & Control & 56 & Stroke & HTN, DM, CAD \\
5 & 65 & Female & JB with P & 40 & Renal infarction & HTN \\
6 & 66 & Female & JB without P & 40 & TIA & none \\
7 & 73 & Male & JB without P & 46 & PAD & HTN, CAD (s/p CABG) \\
8 & 80 & Male & JB without $P$ & 50 & Pulmonary embolism & HTN, DM, CKD, CAD (s/p CABG) \\
9 & 70 & Male & JB without P & 48 & Stroke & HTN, DM, s/p MVR \\
10 & 86 & Male & JB without $P$ & 50 & TIA & HTN \\
11 & 80 & Male & JB without $P$ & 52 & Stroke & HTN, DM, CKD (s/p kidney transplantation), CAD \\
12 & 78 & Female & JB without $P$ & 56 & Stroke & HTN, DM, CAD \\
13 & 88 & Female & JB without $P$ & 46 & Stroke & HTN, DM, CKD, CAD
\end{tabular}

CABG coronary artery bypass graft surgery, CAD coronary artery disease, CKD chronic kidney disease, DM diabetes mellitus, HTN hypertension, JB junctional bradycardia, LAD left anterior descending, MVR mitral valve repair, P P wave, $P A D$ peripheral artery disease, SCD sudden cardiac death, TIA transient ischemic attack

for thromboembolic events is not well understood. In 3 patients who experienced thromboembolic events in the JB without $\mathrm{P}$ group, thromboembolic events did not occur in the immediate postoperative period. Therefore, the events could not be complications associated with cardiac surgery.

Additionally, in the present study, left atrial volume index (LAVI) was significantly larger in the JB group $\left(45 \mathrm{ml} / \mathrm{m}^{2}\right.$ vs. $28 \mathrm{ml} / \mathrm{m}^{2}$ ) than in the control group. The left atrium is highly susceptible to acute and chronic stress factors, such as alterations in both preload and afterload [19]. Reportedly, left atrial volume index is a more accurate parameter for left atrial size than left atrial diameter. Previously, Corbalan et al. reported that left atrial enlargement on two-dimensional echocardiography is a significant independent risk factor for systemic embolism in patients with symptomatic paroxysmal atrial fibrillation [20]. In addition to patients with atrial fibrillation, LAVI has also been shown to be associated with stroke and cardiac thrombi in patients with sinus rhythm or without

Table 4 Independent predictors of thromboembolic events

\begin{tabular}{|c|c|c|c|c|}
\hline & \multicolumn{2}{|l|}{ Univariable } & \multicolumn{2}{|l|}{ Mutivariable } \\
\hline & $\mathrm{HR}(95 \% \mathrm{Cl})$ & $P$ value & $\mathrm{HR}(95 \% \mathrm{Cl})$ & $P$ value \\
\hline \multicolumn{5}{|c|}{ a. Stroke and transient ischemic attack } \\
\hline Male & $0.58(0.14-2.34)$ & 0.472 & & \\
\hline Chronic kidney disease & $1.95(0.48-7.82)$ & 0.352 & & \\
\hline $\mathrm{CHADS}_{2}$ score $\geq 2$ & $5.74(1.17-28.25)$ & 0.032 & $4.67(0.96-22.73)$ & $0.062^{* * *}$ \\
\hline LAVI $\left(\mathrm{ml} / \mathrm{m}^{2}\right)$ & $1.01(0.97-1.06)$ & 0.562 & & \\
\hline$J B^{*}$ & $2.60(0.59-11.53)$ & 0.210 & & \\
\hline$J B$ without $P^{* *}$ & $6.56(1.61-26.75)$ & 0.007 & $8.89(2.20-33.01)$ & $0.002^{* * *}$ \\
\hline \multicolumn{5}{|c|}{ b. Composite thromboembolic events } \\
\hline Male & $0.99(0.36-3.27)$ & 0.993 & & \\
\hline Chronic kidney disease & $1.75(0.54-5.70)$ & 0.352 & & \\
\hline $\mathrm{CHADS}_{2}$ score $\geq 2$ & $3.44(1.04-11.33)$ & 0.043 & $4.07(1.11-14.87)$ & $0.031^{* * *}$ \\
\hline LAVI $\left(\mathrm{ml} / \mathrm{m}^{2}\right)$ & $1.01(0.99-1.03)$ & 0.391 & & \\
\hline$J B$ without $P^{* *}$ & $5.69(1.84-17.63)$ & 0.003 & $5.04(1.68-15.09)$ & $0.004^{* * *}$ \\
\hline
\end{tabular}

$J B$ junctional bradycardia, $L A V I$ left atrial volume index, $P$ P wave

* comparison with the control group

${ }^{*}$ comparison with the control group and JB with $\mathrm{P}$ group

*** adjustment for male sex, $\mathrm{CHADS}_{2}$ score $\geq 2$, and JB without $\mathrm{P}$ group 


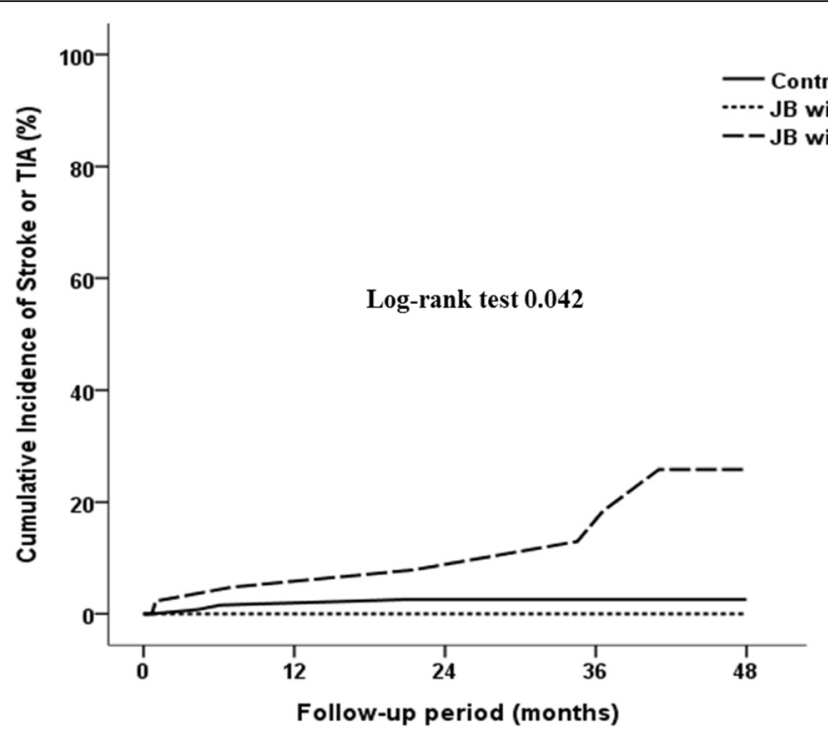

$\begin{array}{lccccc}\text { No. at Risk } & & & & & \\ \text { Control } & 138 & 112 & 90 & 48 & 12 \\ \text { JB with P } & 24 & 21 & 17 & 15 & 10 \\ \text { JB without P } & 45 & 33 & 28 & 16 & 9\end{array}$

Fig. 1 Kaplan-Meier curve of the incidence of stroke at 48 months follow-up after the detection of junctional bradycardia. JB=junctional bradycardia; $P=P$ wave; $T I A=$ transient ischemic attack

atrial fibrillation [21, 22]. Thus, in the JB group, large left atrial volume index could be associated with loss of atrial kick, which might contribute to increased preload of the left atrium.

We used the CHADS 2 scoring system to control for confounding factors in predicting the risk of stroke based on junctional rhythm, since the $\mathrm{CHADS}_{2}$ scheme has been reported as a reliable predictive parameter in patients without atrial fibrillation [23, 24]. $\mathrm{CHADS}_{2}$ score did not predict stroke or thromboembolic events even in subgroup analysis (JB without retrograde $\mathrm{P}$ wave), unlike previous reports in which $\mathrm{CHADS}_{2}$ and $\mathrm{CHA}_{2} \mathrm{DS}_{2}$-VASc scores were associated with an increased risk of stroke in patients with paced sick sinus syndrome [7]. This difference between results could be explained by variation in the study populations.

When patients with JB have co-morbidities that are known risk factors for embolic events, preventive strategies, such as anticoagulant administration or pacemaker implantation, might be considered. However, a randomized controlled study with a large population is also needed to confirm these findings.

\section{Limitations}

There are some limitations to our study. First, it is a retrospective study of a relatively small sample size conducted in a single center. Furthermore, continuous ECG monitoring, such as Holter monitoring, was only performed in about $43 \%$ of the patients with JB; therefore, we could not guarantee the absence of asymptomatic paroxysmal atrial fibrillation in patients without Holter monitoring. Furthermore, because of the very low prevalence of JB and very small number of clinical events, it would be difficult to conclude a robust correlation between JB and clinical events such as stroke. Thus, a large-scale, prospective, observational study is being contemplated.

\section{Conclusions}

Junctional bradycardia is potentially associated with ischemic stroke, particularly in the absence of an identifiable retrograde $\mathrm{P}$ wave.

\section{Abbreviations}

$\mathrm{Cl}$, confidence interval; ECG, electrocardiogram; $\mathrm{HR}$, heart rate; JB with $\mathrm{P}$, junctional bradycardia with $\mathrm{P}$ wave; JB without $\mathrm{P}$, junctional bradycardia without P wave; JB, junctional bradycardia; LAVI, left atrial volume index; TIA, transient ischemic attack

\section{Acknowledgements}

The authors thank Jinae Lee, PhD, and Jung Hwa Hong, MS, from the Biostatistics Collaboration Unit, Yonsei University College of Medicine, for their help with the statistical analyses.

Funding

No funding was obtained in this study.

Availability of data and materials

All the data supporting our findings is contained within the manuscript. 


\section{Authors' contributions}

GSK and JSU were involved in the study design, interpretation of data, drafting and revising of the manuscript. THK, HCL and JBP were participated in data collection, statistical analysis and interpretation of data. JKP and BYJ were involved in the study concept and design. HNP and MHL were involved in the supervision and coordination of the study and revised the manuscript for content. All authors read and approved the final manuscript.

\section{Competing interests}

The authors declare that they have no competing interests.

\section{Consent for publication}

Not applicable.

\section{Ethics approval and consent to participate}

The study design was approved by the Institutional Review Board of Severance Hospital (4-2016-0350) and conducted in compliance with the Declaration of Helsinki. The requirement for informed consent was waived, because of the retrospective nature of the study.

Received: 19 November 2015 Accepted: 22 July 2016

Published online: 25 July 2016

\section{References}

1. Josephson M. Clinical Cardiac Electrophysiology. 4th ed. Philadelphia: Lippincott Williams and Wilkins; 2008.

2. Libby P, Bonow R, Mann D, Zipes. Specific arrhythmias: diagnosis and treatment. In: A Textbook of Cardiovascular Medicine. 8th ed. Philadelphia: Saunders; 2007. p. 640-5.

3. Fairfax AJ, Lambert CD, Leatham A. Systemic embolism in chronic sinoatrial disorder. N Engl J Med. 1976;295:190-2.

4. Fisher M, Kase CS, Stelle B, Mills RM. Ischemic stroke after cardiac pacemaker implantation in sick sinus syndrome. Stroke. 1988;19:712-5.

5. Lang RM, Bierig M, Devereux RB, Flachskampf FA, Foster E, Pellikka PA, Picard MH, Roman MJ, Seward J, Shanewise JS, Solomon SD, Spencer KT, Sutton MS, Stewart WJ, Chamber Quantification Writing G, American Society of Echocardiography's G, Standards C, European Association of E. Recommendations for chamber quantification: a report from the American Society of Echocardiography's Guidelines and Standards Committee and the Chamber Quantification Writing Group, developed in conjunction with the European Association of Echocardiography, a branch of the European Society of Cardiology. J Am Soc Echocardiogr. 2005;18:1440-63.

6. Ujino K, Barnes ME, Cha SS, Langins AP, Bailey KR, Seward JB, Tsang TS. Two-dimensional echocardiographic methods for assessment of left atrial volume. Am J Cardiol. 2006;98:1185-8.

7. Svendsen JH, Nielsen JC, Darkner S, Jensen GV, Mortensen LS, Andersen HR, Investigators D. CHADS2 and CHA2DS2-VASc score to assess risk of stroke and death in patients paced for sick sinus syndrome. Heart. 2013:99:843-8.

8. Hohnloser SH, Pajitnev D, Pogue J, Healey JS, Pfeffer MA, Yusuf S, Connolly SJ, Investigators AW. Incidence of stroke in paroxysmal versus sustained atrial fibrillation in patients taking oral anticoagulation or combined antiplatelet therapy: an ACTIVE W Substudy. J Am Coll Cardiol. 2007:50:2156-61.

9. Greenspon AJ, Hart RG, Dawson D, Hellkamp AS, Silver M, Flaker GC, Schron E, Goldman L, Lee KL, Lamas GA, Investigators MS. Predictors of stroke in patients paced for sick sinus syndrome. J Am Coll Cardiol. 2004;43:1617-22.

10. Wann LS, Curtis AB, Ellenbogen KA, Estes NA, Ezekowitz MD, Jackman WM, January CT, Lowe JE, Page RL, Slotwiner DJ, Stevenson WG, Tracy CM, Fuster V, Ryden LE, Cannom DS, Crijns HJ, Curtis AB, Ellenbogen KA, Halperin JL, Le Heuzey J, Kay GN, Lowe JE, Olsson SB, Prystowsky EN, Tamargo JL, Wann LS. Management of patients with atrial fibrillation (compilation of 2006 ACCF/ AHA/ESC and 2011 ACCF/AHA/HRS recommendations): a report of the American College of Cardiology/American Heart Association Task Force on practice guidelines. Circulation. 2013;127:1916-26.

11. Saksena S, Camm AJ, Boyden P, Dorian P, Goldschlager N Electrophysiological disorders of the heart. Philadelphia: Churchill Livingstone; 2005.

12. Alonso A, Jensen PN, Lopez FL, Chen LY, Psaty BM, Folsom AR, Heckbert SR. Association of sick sinus syndrome with incident cardiovascular disease and mortality: the atherosclerosis risk in communities study and cardiovascular health study. PLoS One. 2014;9:e109662.
13. Koller-Strametz J, Wieselthaler G, Kratochwill C, Laufer G, Pacher R, Heinz G. Thromboembolism associated with junctional escape rhythm and atrial standstill after orthotopic heart transplantation. J Heart Lung Transplant. 1995:14:999-1002.

14. Bennett PC, Silverman SH, Gill PS, Lip GYH. Peripheral arterial disease and Virchow's triad. ThrombHaemost. 2009;101:1032-40.

15. Mor-Avi V, Lang RM, Badano LP, Belohlavek M, Cardim NM, Derumeaux G, Galderisi M, Marwick T, Nagueh SF, Sengupta PP, Sicari R, Smiseth OA, Smulevitz B, Takeuchi M, Thomas JD, Vannan M, Voigt JU, Zamorano JL. Current and evolving echocardiographic techniques for the quantitative evaluation of cardiac mechanics: ASE/EAE consensus statement on methodology and indications endorsed by the Japanese Society of Echocardiography. Eur J Echocardiogr. 2011;12:167-205.

16. Appleton CP, Hatle LK, Popp RL. Relation of transmitral flow velocity patterns to left ventricular diastolic function: new insights from a combined hemodynamic and Doppler echocardiographic study. J Am Coll Cardiol. 1988;12:426-40.

17. Pagel PS, Kehl F, Gare M, Hettrick DA, Kersten JR, Warltier DC Mechanical function of the left atrium: new insights based on analysis of pressure-volume relations and Doppler echocardiography. Anesthesiology. 2003;98:975-94.

18. Vincelj J, Sokol I, Jaksic O. Prevalence and clinical significance of left atrial spontaneous echo contrast detected by transesophageal echocardiography. Echocardiography. 2002;19:319-24.

19. Pavlopoulos H, Nihoyannopoulos P. Left atrial size: a structural expression of abnormal left ventricular segmental relaxation evaluated by strain echocardiography. Eur J Echocardiogr. 2009;10:865-71.

20. Corbalan R, Arriagada D, Braun S, Tapia J, Huete I, Kramer A, Chavez A. Risk factors for systemic embolism in patients with paroxysmal atrial fibrillation. Am Heart J. 1992;124:149-53.

21. Gagne Brosseau MS, Boulanger JM, Leblanc N, Berger L, Benzazon M. Left atrium dilatation and multiple vascular territory strokes. Can J Neurol Sci. 2014:41:704-8.

22. Bakalli A, Georgievska-Ismail L, Kocinaj D, Musliu N, Krasniqi A, Pllana E. Prevalence of left chamber cardiac thrombi in patients with dilated left ventricle at sinus rhythm: the role of transesophageal echocardiography. I Clin Ultrasound. 2013:41:38-45.

23. Lip GY, Lin HJ, Chien KL, Hsu HC, Su TC, Chen MF, Lee YT. Comparative assessment of published atrial fibrillation stroke risk stratification schemes for predicting stroke, in a non-atrial fibrillation population: the Chin-Shan Community Cohort Study. Int J Cardiol. 2013;168:414-9.

24. Ntaios G, Lip GY, Makaritsis K, Papavasileiou V, Vemmou A, Koroboki E, Savvari P, Manios E, Milionis H, Vemmos K. CHADS(2), CHA(2)S(2)DS(2)-VASC, and long-term stroke outcome in patients without atrial fibrillation. Neurology. 2013;80:1009-17.

\section{Submit your next manuscript to BioMed Central and we will help you at every step:}

- We accept pre-submission inquiries

- Our selector tool helps you to find the most relevant journal

- We provide round the clock customer support

- Convenient online submission

- Thorough peer review

- Inclusion in PubMed and all major indexing services

- Maximum visibility for your research

Submit your manuscript at www.biomedcentral.com/submit
) Biomed Central 